\title{
Enhancing the Thermal and Mechanical Properties of Organic- Inorganic Hybrid Nanocomposite Films Based on Poly Lactic Acid/OMMT Nano Clay
}

\author{
S. Mahendra Selvan, D. Duraibabu, A. Gnanaprakasam and S. Ananda Kumar
}

Department of Chemistry, College of Engineering, Anna University, Chennai-600025, India

\begin{abstract}
Organic (PLA) inorganic (OMMT nano clay) hybrid nanocomposite films were fabricated using poly lactic acid (PLA) with various weight percentages (1-3wt\%) of organically modified montmorillonite (OMMT) nano clay by means of one step solvent casting method. The thermal, mechanical and water absorption properties were determined as per standard testing methods to determine the optimum percentage of OMMT nano clay within the nanocomposite was investigated. The surface morphology of the organic-inorganic hybrid nanocomposite films was analyzed through XRD, SEM, and TEM surface analytical techniques. The incorporation of OMMT clay in to PLA matrix is found to have enhanced the thermomechanical properties. The water absorption and solubility test results also support the data from thermomechanical tests. The $2 \mathrm{wt} \%$ OMMT clay loaded PLA films showed the best results among all. The obtained results showed that the thermal, mechanical and water absorption properties could be increased significantly with the optimum incorporation of OMMT nano clay in a PLA matrix, in comparision wih the neat PLA.
\end{abstract}

Received on 30-10-2017 Accepted on 30-11-2017

Published on 10-01-2018

Keywords: PLA, OMMT nano clay, Mechanical properties, Thermal stability, Surface morphology, Water absorption.

\section{INTRODUCTION}

Since the last few years, bioplastics that play an important role in the industrial economies have been regularly used as matrix materials worldwide, [1,2]. Especially for food packaging, an essential part of the economic sector, which deals with high amounts of plastic materials. In general, food packaging materials that are in use are made from petroleum-based raw polymers such as polyethylene (PE), polypropylene (PP), polystyrene (PS), polyethylene terephthalate (PET) and polyvinyl alcohol (PVA) etc., These are the polymers readily available at low cost, possess adequate mechanical and good barrier properties [3-5]. However, petroleum-based polymers have a negative impact as waste plastics in the global environment due to the increasing growth of pollution, wide spreading usage of plastics in our day-to-day life and also more challenging to remove plastic waste in the environment [6-8]. In order to reduce the dependency on petroleum-based polymers, decrease the accumulation of endless plastic waste and simultaneously to control the emission of $\mathrm{CO}_{2}$ in the global environment [9-11], research now is focused on green-bio polymer like poly (lactic acid) PLA, which will have direct

"Department of Chemistry, College of Engineering, Anna University, Chennai600025, India; Tel: +91 44-22358661; Fax: 91-44-22200660;

E-mail: sri_anand_72@yahoo.com impact on environment and high profit margin for corporate sector. PLA is one of the supreme outstanding materials to substitute petroleum-based raw materials, which can reduce the carbon footprint and waste hazard to the global environment. The nomenclature of the PLA is an alphabetic thermoplastic polymer, derived from agricultural sugar feedstocks like corn, sugar beet, and other agricultural products etc., [12,13]. PLA being remarkable finds application in various areas such as drug delivery, bio-medical, food packaging, agriculture, cutleries, etc., Furthermore, PLA is brittle in nature, with low mechanical, thermal properties and imparts uncontrollable degradation pattern, which restrict its utility for food packaging materials. In order to overcome the above said properties of PLA and to make it suitable for food packaging applications, different strategies such as blending of PLA with flexible biodegradable polymers like polycaprolactone (PCL), poly (butylene succinate) (PBS), poly (butylene adipate-co-terephthalate) (PBAT) etc., were reported in the literature $[14,15]$. Nonetheless, the addition of toughening polymer into the PLA matrix consequently decreases the tensile strength and modulus properties of PLA, [16]. The bitter truth is none of these methods seem to have improved the toughness of PLA without the loss of rigidity [17]. Quite recently PLA has been modified with nanoparticles to have good toughness and strength balanced by proper dispersion phase morphology and interfacial 
properties between the components [18, 19]. Furthermore, the introduction of nanofillers such as clay minerals, carbon nanotubes, and graphene etc., into the PLA matrix, can enhance its properties in terms of mechanical, thermal, gas barrier, optical and antimicrobial properties [20, 21]. The rationale of this present work is to modify PLA by reinforcing it with organically modified MMT (OMMT) nano clay, thereby making organic- inorganic hybrid PLA-OMMT nanocomposite films with properties that are ideally suited for food packaging application. Thus PLA films incorporated with OMMT clay will have better properties when compared with the neat PLA film. PLA flexible films are developed in the present work using solvent casting method. The mechanical, thermal and water absorption properties are studied using tensile test and thermo-gravimetric analysis, thereby determining the optimum percentage of OMMT clay to be loaded in PLA matrix. The surface morphology of the organic-inorganic hybrid nanocomposite films was investigated by means of SEM and TEM analysis. The scope of this work is to extend the level and usage of PLA in packaging and other outdoor applications.

\section{EXPERIMENTAL SECTION}

\section{Materials Required}

PLA, Ingeo ${ }^{\text {TM }}$ Biopolymer 3052D was bought from Natur Tec India Pvt. Ltd., MMT clay was bought from Sigma Aldrich. Zinc Stearate (with ZnO 12.5 - $14 \%$ ) and silver nitrate were bought from Alfa Aesar. Tetrahydrofuran (THF), benzene, dimethyl sulfoxide (DMSO), acetone, ethyl acetate, chloroform, diethyl ether and petroleum ether were obtained from SD fine chemical company, India.

\section{Synthesis of Na-MMT Clay}

Crude (MMT) clay was dispersed into the stoichiometric amount of $\mathrm{NaCl}$ solution. Stirring was continued for $24 \mathrm{hr}$ at $70^{\circ} \mathrm{C}$. After that the solution mixture was centrifuged at high speed till an opaque whitish layer accumulates obtained at the bottom of the centrifuge tubes beneath a translucent gel. The resultant gel was removed and isolated. The whitish layer was washed with distilled water several times until no chlorine was detected in the centrifuged. The purified clay was further dried at $70^{\circ} \mathrm{C}$ and stored in a desiccator. [22]

\section{Synthesis of Organically Modified Montmorillonite (OMMT) Nano Clay}

Na-MMT clay was dispersed into distilled water and mixed for $24 \mathrm{hr}$ and then $200 \mathrm{ml}$ of diethyl ether solution and $5.6 \mathrm{~g}$ of zinc stearate was slowly poured into the clay dispersion. The resulting system contained a clear upper organic layer and a turbid bottom mineral phase. After a $12 \mathrm{hr}$ of moderate mixing, the mineral phase became transparent and the organic phase became turbid. Special care was taken to avoid diethyl ether evaporation. At this point, the system was warmed up to evaporate the diethyl ether, using a rotoevaporator. After solvent evaporation, the organic phase became a sticky solid precipitate. The precipitated organoclay was filtered and dispersed in hot water $\left(80^{\circ} \mathrm{C}\right)$ for $4 \mathrm{hr}$. Washing was repeated three times, until no chloride traces were detected with silver nitrate after the third washing. The resulting organoclay paste was manually mixed with $40 \mathrm{ml}$ of petroleum ether using a spatula. After free petroleum ether evaporation, the organoclay was dried at $80^{\circ} \mathrm{C}$, grounded using a pestle mortar and stored [23].

\section{Optimization of Film Formation}

The film formation was done using different solvents before optimizing the film formation. The films formed using different solvents have different textures, opacity, and strength. Observation and inference made during the optimization of the film are illustrated in Figure 1. The film formed using chloroform was found to have the characteristics of flexibility,
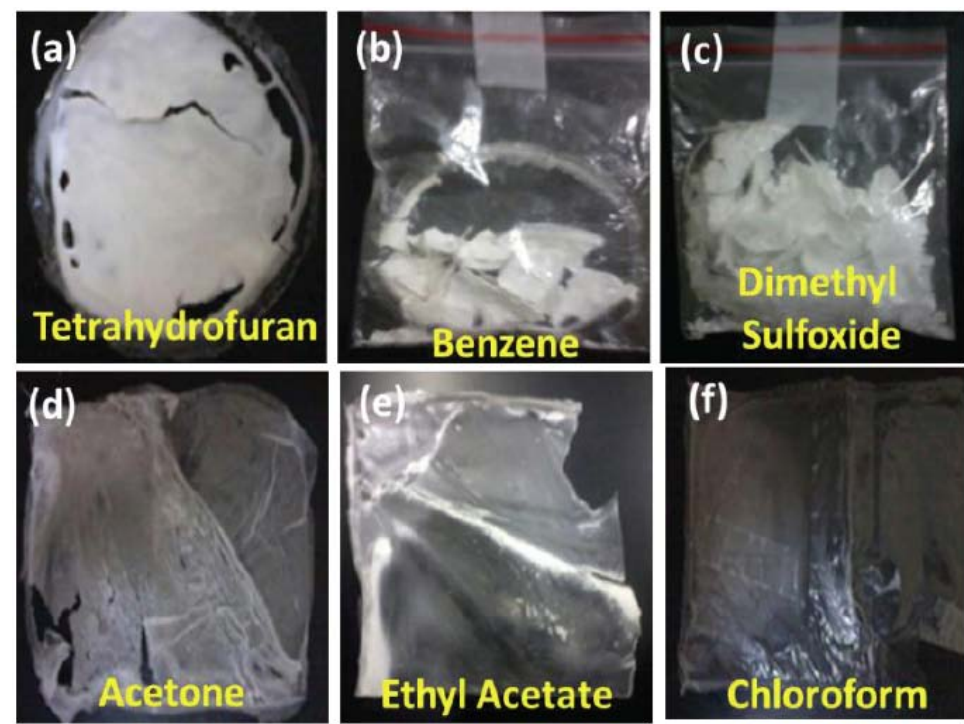

Figure 1: Optimization of film formation. 
translucent to transparent and also tough. With these observations, chloroform was chosen as an ideal solvent for the preparation of PLA films.

\section{Preparation of Organic-Inorganic Hybrid Nanocomposite (PLA-OMMT) Films}

Organic-inorganic hybrid nanocomposite films were prepared by solvent casting method as follows: $2.0 \mathrm{~g}$ of neat PLA was mixed in $100 \mathrm{ml}$ of chloroform solvent and the mixture was continuously stirred for $2 \mathrm{hr}$ using a magnetic stirred at room temperature until a transparent solution was obtained. The obtained product of PLA solution was mixed with different weight percentage of OMMT nano clay (1, 2 and $3 w t \%)$ (Table 1), and was kept in an ultra-sonication of 70 mins until a homogeneous solution was obtained. The resultant product was poured into Petri dishes to get thin films which were further dried under ambient condition to slowly evaporate the solvent for $24 \mathrm{~h}$ [24]. The final organic-inorganic hybrid (PLAOMMT) nanocomposite films obtained were further dried in an oven under vacuum at $40^{\circ} \mathrm{C}$ for $24 \mathrm{hr}$ (Figure 2).

Table 1: Nomenclature of the Organic-Inorganic Hybrid Nanocomposite Films

\begin{tabular}{|c|c|c|}
\hline Systems & PLA/wt\% of OMMT nano clay & Solvent \\
\hline \hline a & $100 / 0$ & Chloroform \\
\hline b & $100 / 1 \%$ & Chloroform \\
\hline c & $100 / 2 \%$ & Chloroform \\
\hline d & $100 / 3 \%$ & Chloroform \\
\hline
\end{tabular}

\section{CHARACTERIZATION}

\section{Mechanical Analysis}

The tensile properties of the solution casting organicinorganic hybrid nanocomposite films were determined as per ASTM method using an Instron Mechanical Tester (Model 5564 ) at a crosshead speed of $5 \mathrm{~mm} / \mathrm{min}$ at room temperature. The specimens were prepared by cutting strips $20 \mathrm{~mm}$ wide by $110 \mathrm{~mm}$.

\section{Thermal Gravimetric Analysis (TGA)}

Thermo-gravimetric analysis of organic-inorganic hybrid nanocomposite films was carried out using TGA-Thermal Analyst NETZSCH STA 409 PC (TA instruments, USA) at a heating rate of $10^{\circ} \mathrm{C} / \mathrm{min}$ from $0^{\circ} \mathrm{C}$ to $800^{\circ} \mathrm{C}$ under a continuous flow of $\mathrm{N}_{2}$ atmosphere to determine thermal degradation temperature, percentage weight loss and char yield formation. About $5 \mathrm{mg}$ of samples were taken for each analysis.

\section{X-Ray Diffraction (XRD)}

XRD patterns were recorded for Na-MMT clay, OMMT clay, neat PLA and PLA/OMMT nano clay films having varied percentages at room temperature by monitoring the diffraction angle $2 \theta$ from $10^{\circ}$ to $70^{\circ}$ as a standard and $0.5^{\circ}$ to $10^{\circ}$ as a low angle on a Rich Seifert (Model 3000) X-ray powder diffractometer. The diffractometer was equipped with a Copper target $(\lambda 1.5405 \AA)$ radiation using Guinier type camera used as focusing geometry and a solid state detector. The curved nickel crystal was used as the monochromator. The step width (scanning speed) used was $2 \theta=0.04 \mathrm{deg} / \mathrm{min}$.

\section{Scanning Electron Microscopy (SEM)}

A JEOL JSM-6360 scanning electron microscope was used for the sample analysis and the fractured samples were prepared by coating gold on the surface of the samples and analyzed further.

\section{Transmission Electron Microscopy (TEM)}

A JEOL JEM-3010 analytical transmission electron microscope, operating at $300 \mathrm{kV}$ with a measured point-topoint resolution of $0.23 \mathrm{~nm}$, was used to characterize the phase morphology of the organic-inorganic hybrid nanocomposite films. TEM samples were prepared by dissolving polymers in DMF mounted on a carbon-coated $\mathrm{Cu}$ TEM grids and dried $24 \mathrm{~h}$ at room temperature (RT) to form a film in $<100 \mathrm{~nm}$ size.

\section{Water Absorption Test}

The water absorption measurements of organic-inorganic hybrid nanocomposite films were carried out according to ASTM D570-81 for $24 \mathrm{~h}$ at $25^{\circ} \mathrm{C}$ and the percentage of water absorbed by the specimens was calculated using the following equation (1).

$\%$ water absorption $=\left(\mathrm{W}_{2}-\mathrm{W}_{1}\right) \times 100 / \mathrm{W}_{1}$

Where, $W_{1}$ is the initial weight of the sample and

$\mathrm{W}_{2}$ is the weight of the sample after immersion in water for 24 $\mathrm{h}$ at $25^{\circ} \mathrm{C}$.

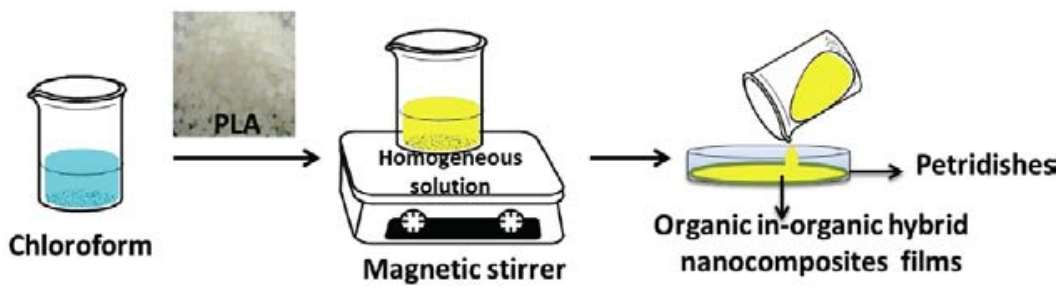

Figure 2: Schematic diagram of sample preparation. 


\section{RESULTS AND DISCUSSION}

\section{Mechanical Analysis}

Figure 3 shows the mechanical properties of organicinorganic hybrid nanocomposite films with different OMMT nano clay contents obtained from the tensile test. The tensile stress of the organic-inorganic hybrid nanocomposite films increased remarkably with the addition of OMMT nano clay content and possesses a maximum value up to $2 \mathrm{wt} \%$ of OMMT nano clay are illustrated in Figure $\mathbf{3}$ and Table $\mathbf{2}$ respectively. It can be clearly seen from Figure $\mathbf{3}$ and Table $\mathbf{2}$ that the tensile strength values of systems ' $b$ ' and ' $c$ ' increased to $5.4 \mathrm{Mpa}$ and $6.3 \mathrm{Mpa}$ respectively with increasing OMMT nano clay content, which was found to be higher than that of the neat PLA film (4.7 Mpa). This might be due to the uniform distribution (Figure $6 \mathbf{a}$ ) and interaction of OMMT nanoclay $[25,26]$ within the PLA matrix. However, system ' $d$ ' having $3 w t \%$ of OMMT clay showed a slight decreased value of tensile strength compared to other systems ' $a$ ' and ' $b$ ' are shown in Figure 3. This could be due to the improper dispersion (Figure $6 \mathbf{b}$ ) of higher weight percentage loaded OMMT nano clay of $3 w t \%$, which led to agglomeration and subsequently cracks were initiated, and the cracks tend to propagate inside the agglomerated PLA matrix [27]. It was interesting to notice that the elongation at break has also increased with an increase in the OMMT nano clay up to $2 \mathrm{wt} \%$ corresponds to the maximum value at $37.17 \%$, whereas the elongation at break for neat PLA film was found to be $1.32 \%$ and $4.50 \%$ for system 'd' respectively (Table 2). Thus, it can be concluded from the above observations that an optimum introduction of OMMT nano clay in the PLA matrix could enhance both strengthening and toughening of the PLA due to the homogeneous dispersion (Figure 6a) of OMMT nano clay within the PLA. A similar trend was observed by Bouakaz et al. [28].

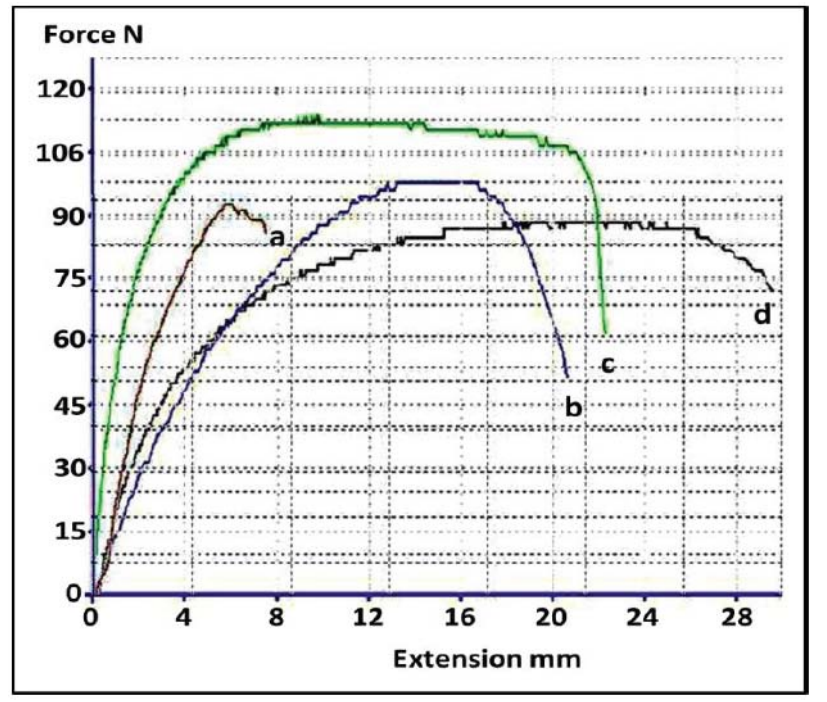

Figure 3: Tensile Tests of systems (a) neat PLA film (b) PLA/1wt\% of OMMT nano clay film (c) PLA/2wt\% of OMMT nano clay film and (d) PLA/3wt \% of OMMT nano clay film.
Table 2: Data Resulted from Mechanical Properties of Organic-Inorganic Hybrid Nanocomposite Films

\begin{tabular}{|c|c|c|c|}
\hline Systems & $\begin{array}{c}\text { PLA/wt\% of OMMT } \\
\text { nano clay }\end{array}$ & $\begin{array}{c}\text { Tensile } \\
\text { Stress (Mpa) }\end{array}$ & $\begin{array}{c}\text { Elongation at } \\
\text { break (\%) }\end{array}$ \\
\hline \hline a & $100 / 0$ & $4.7 \pm 1$ & 1.32 \\
\hline b & $100 / 1 \%$ & $5.4 \pm 7$ & 3.43 \\
\hline c & $100 / 2 \%$ & $6.3 \pm 1$ & 37.17 \\
\hline$d$ & $100 / 3 \%$ & $5.2 \pm 8$ & 4.50 \\
\hline
\end{tabular}

\section{Thermo-gravimetric Analysis (TGA)}

TGA analysis was carried out in order to investigate the effect of OMMT nano clay on the thermal stability of organicinorganic hybrid nanocomposite films are presented in Table 3 and Figure 4 respectively. It can be seen that the initial degradation temperatures (IDT) along with char residue for systems ' $b$ ' and ' $c$ ' were increased to $334^{\circ} \mathrm{C}$ to $341^{\circ} \mathrm{C}$ with the increasing loading of OMMT nano clay, when compared with the neat PLA film whose IDT value was $329^{\circ} \mathrm{C}$. Generally the introduction of inorganic components (OMMT nano clay) into organic (PLA) materials can significantly improve their thermal stabilities. Higher thermal stability of organicinorganic hybrid (PLA-OMMT) nanocomposite films may be attributed to presence and interaction of inorganic nano particles with the organic polymer matrix. It was interesting note that the systems ' $b$ ' and ' $c$ ' imparted better thermal stability when compared with all systems of the present study. This increase in thermal stability observed in the case of system ' $b$ ' and ' $c$ ' could be attributed to the uniform distribution of OMMT nano clay within the PLA matrix [29, 30]. These results were in good agreement with tensile strength (Figure 3), SEM and TEM results (Figure 6). A similar observation was reported by Ogata et al. [31]. However, under higher loading of $3 w t \%$ (system ' $d$ ') of OMMT nano clay loaded PLA nanocomposite film showed a slightly decreased thermal stability compared to the systems ' $b$ ' and 'c'. The inferior thermal stability imparted by system 'c' could be attributed to the high content of inorganic particles (OMMT nano clay) that formed agglomeration within the PLA films [32]. From the above observations, we conclude that an optimum wt\% loading of OMMT nano clay in PLA can enhance both IDT and char residue.

Table 3: Data on Thermal Properties of Organic-Inorganic Hybrid Nanocomposite Films

\begin{tabular}{|c|c|c|c|}
\hline Systems & $\begin{array}{c}\text { PLA/wt\% of } \\
\text { OMMT nano clay }\end{array}$ & $\begin{array}{c}\text { Initial decomposition } \\
\text { Temperature }\left({ }^{\circ} \mathrm{C}\right)\end{array}$ & $\begin{array}{c}\text { Char yield } \\
(\%)\end{array}$ \\
\hline \hline a & $100 / 0$ & 329 & 1.14 \\
\hline b & $100 / 1 \%$ & 334 & 4.4 \\
\hline c & $100 / 2 \%$ & 341 & 7.2 \\
\hline d & $100 / 3 \%$ & 336 & 12.5 \\
\hline
\end{tabular}




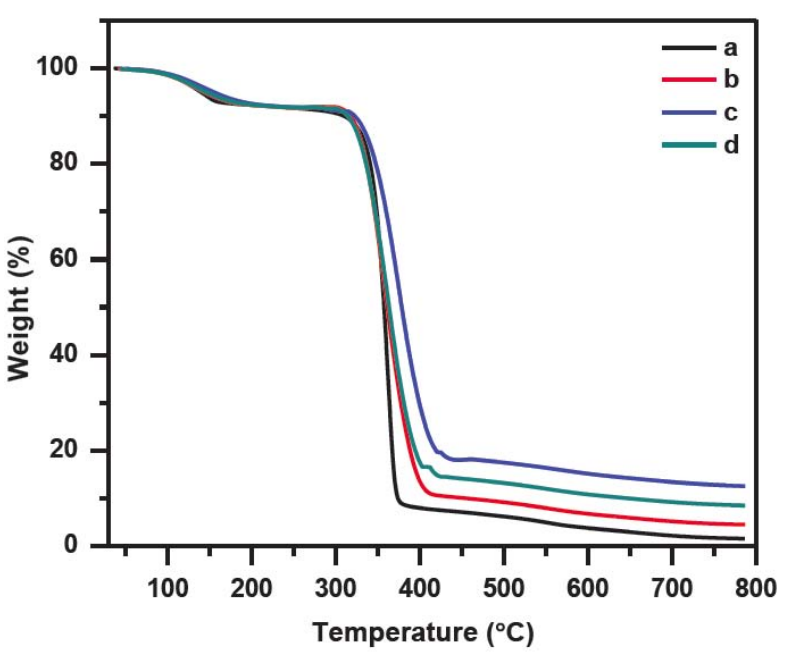

Figure 4: TGA of systems (a) neat PLA film (a) neat PLA film (b) PLA/1wt\% of OMMT nano clay film (c) PLA/2wt\% of OMMT nano clay film and (d) PLA $/ 3 w t \%$ of OMMT nano clay film.

\section{XRD Analysis}

X-Ray Diffraction (XRD) analysis was carried out for the neat PLA films and different weight percentage OMMT nano clay loaded PLA nanocomposite films. The results are illustrated in Figure 5. The XRD patterns obtained for organic in-organic hybrid nanocomposite films (systems 'b', 'c' and 'd') were found to exhibit a mixed intercalated and exfoliated behavior with different interlayer spacing morphology. It was observed that upon increasing OMMT nano clay concentration within the PLA films, the $2 \theta$ value shifted towards the lower angle indicating that the OMMT nano clay platelets were not fully exfoliated but intercalated towards greater extent. Similar observations were made by Najafi et al. 2015 [33].

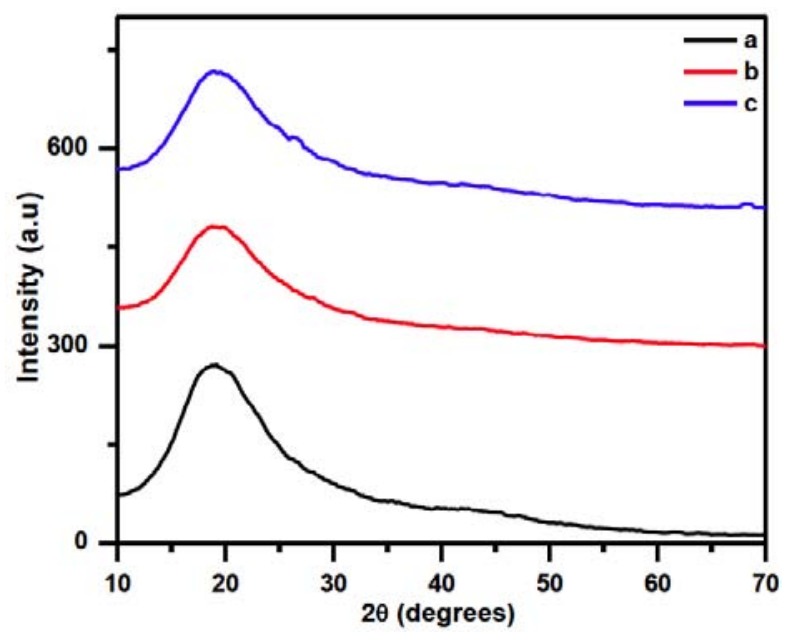

Figure 5: XRD of systems (a) neat PLA film (b) PLA/1wt\% of OMMT nano clay film (c) PLA/2wt \% of OMMT nano clay film.

\section{SEM and TEM Analysis}

The tensile fractured surface morphology of organic-inorganic hybrid nanocomposite films (systems 'b', 'c' and ' $d$ ') is presented in Figure 6. From the Figure, we can clearly see the fractured surface morphology of system 'b' (2 wt\%) depicts uniformly dispersed OMMT nano clay in the PLA (Figure 6a). This uniform dispersion of OMMT nano clay within PLA may be the reason for the effective chemical interaction between PLA and OMMT nano clay [34, 35]. Because of which an enhancement in tensile strength and thermal stability of system 'b' was noticed. However, the higher loading of $3 w t \%$ OMMT nano clay with PLA (system 'd') offered improper dispersion (Figure 6b) that led to decreased mechanical and thermal properties [36, 37].

\section{Water Absorption Test}

The rate of water absorption of the neat PLA film and organic-inorganic hybrid nanocomposite films (systems ' $b$ ', 'c' and ' $d$ ') are presented in Table $\mathbf{4}$ and Figure 7 respectively. It can be seen that the water absorption properties decreased with increased percentage of OMMT nano clay. For example, the lower water uptake values observed for the systems ' $b$ ' (3.6) ' $c$ ' (2.8) and ' $d$ ' (1.8) when compared to neat PLA film system 'a' whose water absorption value was found to be the maximum (4.3) among all other systems (Table 4). This may be due to the presence of inorganic groups of OMMT that acted as barrier, thereby providing protected pathways to the entry of water molecules thus leading to a reduced hydrophilicity in systems 'b', 'c' and 'd' respectively [38].

\section{CONCLUSION}

Organic-inorganic hybrid nanocomposite films were prepared by one-step solvent casting method. The thermal, mechanical and water absorption properties of nanocomposite films were determined as per standard testing methods in comparision with the neat PLA film to determine the optimum percentage loading of OMMT nano clay within the PLA-OMMT nanocomposite composition. The surface morphology of the organic-inorganic hybrid nanocomposite films was analyzed through XRD, SEM, and TEM surface analytical techniques. The obtained results showed that the thermal, mechanical and water absorption properties could be increased significantly with the optimum incorporation of OMMT nano clay in a PLA matrix, in comparision with the neat PLA. The optimized OMMT-PLA nanocomposite film (system 'c' of $2 w t \%$ of OMMT nano clay loaded PLA film) imparted superior mechanical, thermal and water resistant behaviour when compared to the $3 w t \%$ OMMT loaded PLA film (system ' $d$ '). The surface morphology of organic-inorganic hybrid nanocomposite films (b, $c$, and d) from SEM was found to exhibit surface roughness and the surface roughness increases up to $3 \mathrm{wt} \%$ of OMMT nano clay concentration, which in turn increases torturous path to crack propagation. Based on the data obtained from the above study, we conclude that the $2 \mathrm{wt} \%$ OMMT nano clay loaded PLA nanocomposite films could be tried as a possible replacement for conventional and commercial packaging materials that are currently being used. 

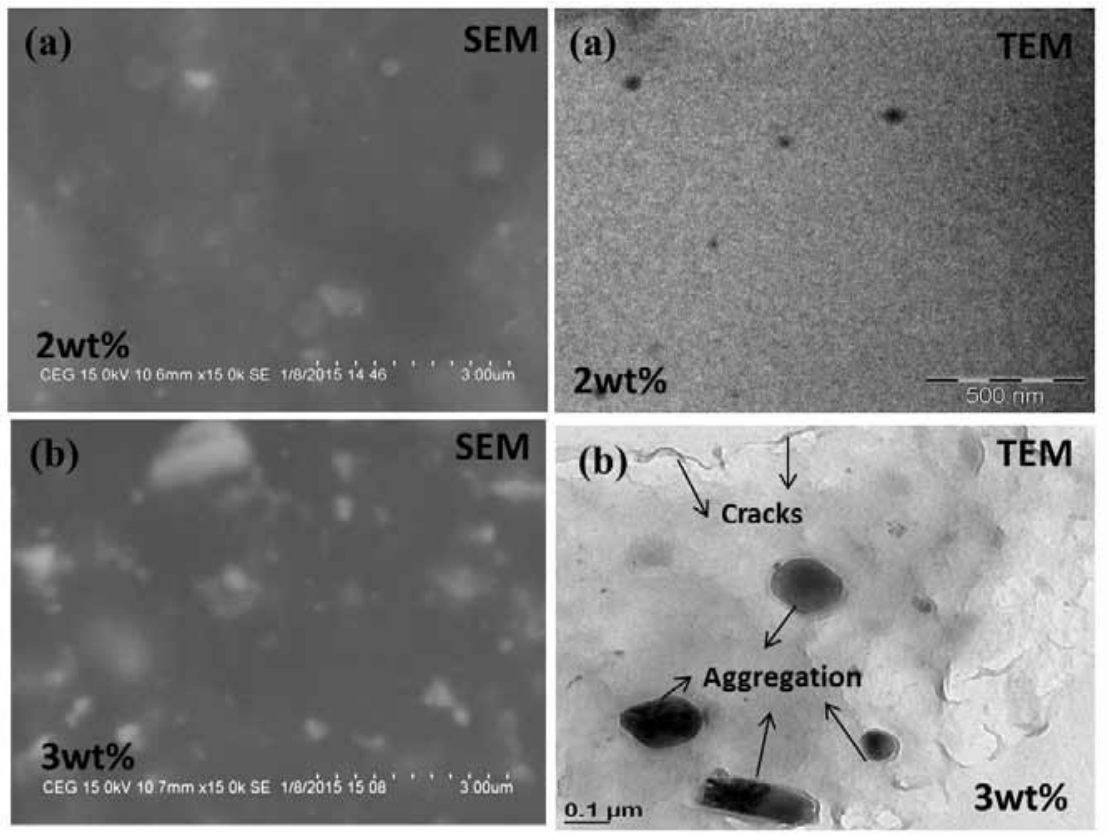

Figure 6: SEM and TEM photographs of systems (a) PLA/2wt\% of OMMT nano clay film and (b) PLA/3wt\% of OMMT nano clay film.

Table 4: Data on Water Absorption of Organic-Inorganic Hybrid Nanocomposite Films

\begin{tabular}{|c|c|c|}
\hline Systems & PLA/wt\% of OMMT nano clay & Water absorption \\
\hline \hline a & $100 / 0$ & 4.3 \\
\hline b & $100 / 1 \%$ & 3.6 \\
\hline c & $100 / 2 \%$ & 2.8 \\
\hline d & $100 / 3 \%$ & 1.8 \\
\hline
\end{tabular}

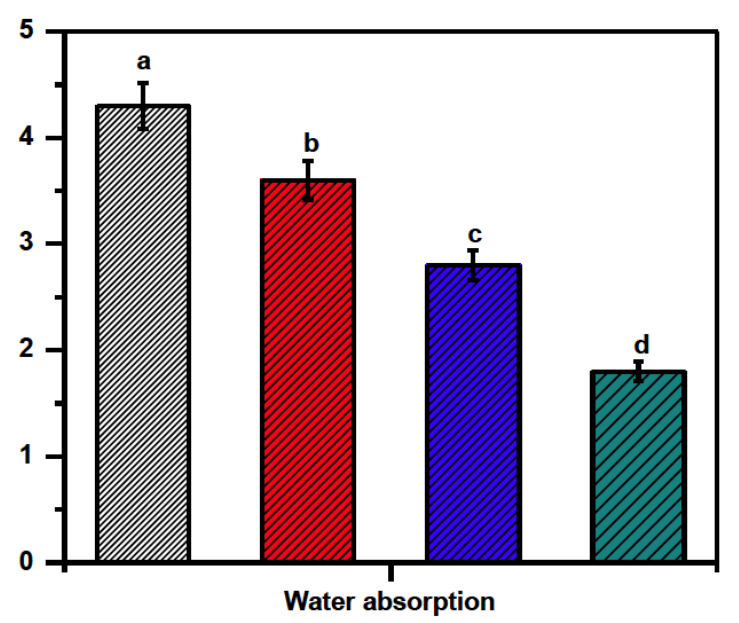

Figure 7: Water absorption of systems (a) neat PLA film (b) PLA/1wt\% of OMMT nano clay film (c) PLA/2wt\% of OMMT nano clay film and (d) PLA/3wt $\%$ of OMMT nano clay film.

\section{ACKNOWLEDGEMENTS}

Instrumentation facility provided under FIST-DST and DRSUGC to Department of Chemistry, Anna University, Chennai is gratefully acknowledged.

\section{REFERENCES}

[1] Carol TM, Pellegrino J, Paster MD. Opportunities in the industria biobased products. Applied Biochemistry and Biotechnology 2004; 113: $871-885$ https://doi.org/10.1385/ABAB:115:1-3:0871

Molinaro S, Romero MC, Boaro M, Sensidoni A, Lagazio C, Morrise M, Kerry J. Effect of nanoclay-type and PLA optical purity on the characteristics of PLA-based. Journal of Food Engineering 2013; 117 : 113-123. https://doi.org/10.1016/i.jfoodeng.2013.01.021

[3] Badía JD, Strömberg E, Ribes-Greus A, Karlsson S. Assessing the MALDI-TOF MS sample preparation procedure to analyze the influence of thermo-oxidative ageing and thermo-mechanical degradation on poly(lactide). Eur Polym J 2011; 47(7): 1416-1428. https://doi.org/10.1016/j.eurpolymj.2011.05.001

[4] Bouwmeester $\mathrm{H}$, Hollman PC, Peters RJ. Potential Health Impact of Environmentally Released Micro- and Nanoplastics in the Human Food Production Chain: Experiences from Nanotoxicology. Environmental Science Technology 2015; 49: 8932-8947.

https://doi.org/10.1021/acs.est.5b01090

[5] Koelmans AA, Bakir A, Burton GA, Janssen CR. Microplastic as a Vector for Chemicals in the Aquatic Environment: Critical Review and Model-Supported Reinterpretation of Empirical Studies. Environmental Science Technology 2016; 50: 3315-3326. https://doi.org/10.1021/acs.est.5b06069

[6] Araújo A, Botelho G, Oliveira M, Machado AV. Influence of clay organic modifier on the thermal-stability of PLA based nanocomposite. Applied Clay Science 2014; 88-89: 144-150. https://doi.org/10.1016/i.clay.2013.12.005

[7] Niu $X$, Liu $Y$, Song $Y$, Han J, Pan $H$. Rosin modified cellulose nanofiber as a reinforcing and co-antimicrobial agents in polylactic acid /chitosan composite film for food packaging. Carbohydrate Polymers 2018; 183(1): 102-109.

https://doi.org/10.1016/j.carbpol.2017.11.079

[8] Bouakaz BS, Habi A, Grohens Y, Pillin I. Organomontmorillonite/ graphene-PLA/PCL nanofilled blends: New strategy to enhance the functional properties of PLA/PCL blend. Applied Clay Science 2017; 139: 81-91.

https://doi.org/10.1016/i.clay.2017.01.014

[9] Nampoothiri KM, Nair NR, John RP. An overview of the recent developments in polylactide (PLA) research. Bioresource Techno 2010; 101(22): 8493-501.

https://doi.org/10.1016/j.biortech.2010.05.092

[10] Mikos AG, Thorsen AJ, Czerwonka LA, Bao Y, Langer R, Winslow $\mathrm{DN}$, et al. Preparation and characterization of poly(L-Lactic Acid) foams. Polymer 1994; 35(5): 1068-77

https://doi.org/10.1016/0032-3861(94)90953-9 
[11] Zhao $H$, Cui $Z$, Wang $X$, Turng L-S, Peng $X$. Processing and characterization of solid and microcellular poly(lactic acid)/polyhydroxybutyrate-valerate (PLA/PHBV) blends and PLA/PHBV/Clay nanocomposite. Composites: Part B 2013; 51: 79-91. https://doi.org/10.1016/i.compositesb.2013.02.034

[12] Lim LT, Auras R, Rubino M. Processing technologies for poly(lactic acid). Prog Polym Sci 2008; 33: 820-852. https://doi.org/10.1016/i.progpolymsci.2008.05.004

[13] De Silva RT, Pasbakhsh P, Mae LS, Kit AY. ZnO deposited/encapsulated halloysite-poly (lactic acid) (PLA) nanocomposite for high performance packagingfilms with improved mechanical and antimicrobial properties. Applied Clay Science 2015; 111: $10-20$.

https://doi.org/10.1016/i.clay.2015.03.024

[14] Urquijo J, Guerrica-Echevarr Ia G, Eguiazabal Jl. Melt processed PLA/PCL blends:Effect of processing method on phase structure, morphology, and mechanical properties. J Appl Polym Sci 2015; 132: 42641 . https://doi.org/10.1002/app.42641

[15] Zhang N, Zeng C, Wang L, Ren J. Preparation and properties of biodegradable poly(lactic acid)/poly(butylene adipate-coterephthalate) blend with epoxyfunctional styrene acrylic copolymer as reactive agent. J Polym Environ 2012; 21: 286-292. https://doi.org/10.1007/s10924-012-0448-z

[16] Zhou Y, Lei L, Yang B, Li J, Ren J. Preparation of PLA-based nanocomposite modified by nanoattapulgite with good toughnessstrength balance. Polymer Testing 2017; 60: 78-83. https://doi.org/10.1016/i.polymertesting.2017.03.007

[17] Duraibabu D, Madhumitha V, Alagar M, Kumar SA, Abhinandan S. Development and Characterization of a Novel Skeletal Modified Tetraglycidyl Epoxy Toughened DGEBA Epoxy Matrices Polymer Science Ser A 2014; 56: 480-487. https://doi.org/10.1134/S0965545X1404004X

[18] Gu JRSY, Dong B. Melt rheology of polylactide/montmorillonite nanocomposite. J Polym Sci B-Polym Phys 2007; 45: 3189-3196. https://doi.org/10.1002/polb.21317

[19] Yu F, Huang HX. Simultaneously toughening and reinforcing poly(lactic acid)/thermoplastic polyurethane blend via enhancing interfacial adhesion by hydrophobic silica nanoparticles. Polym Test 2015; 45: 107-113. https://doi.org/10.1016/i.polymertesting.2015.06.001

[20] Rhim J-W, Hong S-I, Ha C-S. Tensile, water vapor barrier and antimicrobial properties of PLA/nanoclay compositefilms. LWT-Food Sci Technol 2009; 42(2): 612-7.

https://doi.org/10.1016/j.lwt.2008.02.015

[21] Aghjeh MR, Kazerouni Y, Otadi M, Khonakdar HA, Jafari SH, EbadiDehaghani $\mathrm{H}$, Mousavi SH. A combined experimental and theoretical approach to quantitative assessment of microstructure in PLA/PP/Organo-Clay nanocomposite; wide-angle $x$-ray scattering and rheological analysis. Composites Part B 2018; 137: 235-246. https://doi.org/10.1016/i.compositesb.2017.10.036

[22] Dhanapal D, Selvarasu V, Muthu Karuppan A, Srinivasan AK. Synthesis and Characterization of New Ether Linked Tetraglycidyl Epoxy Silicate Nanocomposite, Silicon, 2014

https://doi.org/10.1007/s12633-014-9183-5

[23] Duraibabu D, Rajagopal D, Kumar SA. A first MMT reinforced nanocomposite functionalized with ether linkage derived from tetraglycidyl/diglycidyl epoxy building block. Progress in Organic Coatings 2017; 104: 135-140.

https://doi.org/10.1016/i.porgcoat.2016.12.014

[24] Narayanan M, Loganathan S, Valapa RB, Thomas S, Varghese TO. UV protective poly(lactic acid)/rosin films for sustainable packaging. International Journal of Biological Macromolecules 2017; 99: 37-45. https://doi.org/10.1016/i.iibiomac.2017.01.152
[25] Krishnaiah P, Ratnam CT, Manickam S. Development of silane grafted halloysite nanotube reinforced polylactide nanocomposite for the enhancement of mechanical, thermal and dynamic-mechanical properties. Applied Clay Science 2017; 135: 583-595 https://doi.org/10.1016/i.clay.2016.10.046

[26] Arjmandi R, Hassana A, Mohamad Haafizb MK, Zakaria Z. Partial replacement effect of montmorillonite with cellulose nanowhiskers on polylactic acid nanocomposite. International Journal of Biological Macromolecules 2015; 81: 91-99.

https://doi.org/10.1016/i.ijbiomac.2015.07.062

[27] Wang L, Qiu J, Sakai E, Wei X. The relationship between microstructure and mechanical properties of carbon nanotubes/polylactic acid nanocomposite prepared by twin-screw extrusion. Composites: Part A 2016; 89: 18-25.

https://doi.org/10.1016/i.compositesa.2015.12.016

[28] Bouakaz BS, Habi A, Grohens Y, Pillin I. Organomontmorillonite/ graphene-PLA/PCL nanofilled blends: New strategy to enhance the functional properties of PLA/PCL blend. Applied Clay Science 2017; 139: 81-91.

https://doi.org/10.1016/i.clay.2017.01.014

[29] Arjmandi R, Hassana A, Haafizb MKM, Zakaria Z, Md. Islam S. Effect of hydrolysed cellulose nanowhiskers on properties of montmorillonite/polylactic acid nanocomposite. International Journal of Biological Macromolecules 2016; 82: 998-1010.

https://doi.org/10.1016/.ijbiomac.2015.11.028

[30] Arjmandi R, Hassan A, Haafiz MKM, Zakaria Z. Partial replacement effect of montmorillonite with cellulose nanowhiskers on polylactic acid nanocomposite. Int J Biol Macromol 2015; 81: 91-99. https://doi.org/10.1016/j.ijbiomac.2015.07.062

[31] Ogata N, Jimenez G, Kawai H, Ogihara T, J of Polym Science: Part B: Polymer Physics 1997; 35: 389-396. https://doi.org/10.1002/(SICl)1099-0488(19970130)35:2<389::AIDPOLB14>3.0.CO;2-E

[32] Ebadi-Dehaghani $\mathrm{H}$, Barikani $\mathrm{M}$, Khonakdar $\mathrm{HA}$, Jafari $\mathrm{SH}$ Wagenknecht $\mathrm{U}$, Heinrich $\mathrm{G}$. On $\mathrm{O}_{2}$ gas permeability of PP/PLA/clay nanocomposite: A molecular dynamic simulation approach. Polyme Testing 2015; 45: 139-151. https://doi.org/10.1016/i.polymertesting.2015.05.010

[33] Najafi N, Heuzey M-C, Carreau PJ, Therriault D, Park CB. Mechanical and morphological properties of injection molded linear and branchedpolylactide (PLA) nanocomposite foams. European Polymer Journal 2015; 73: 455-465.

https://doi.org/10.1016/i.eurpolymi.2015.11.003

[34] Zhou Y, Lei L, Yang B, Li J, Ren J. Preparation of PLA-based nanocomposite modified by nanoattapulgite with good toughnessstrength balance. Polymer Testing 2017; 60: 78-83. https://doi.org/10.1016/j.polymertesting.2017.03.007

[35] Scaffaro R, Botta L, Maio A, Gallo G. PLA graphene nanoplatelets nanocomposite: Physical properties and release kinetics of an antimicrobial agent. Composites Part B 2017; 109: 138-146. https://doi.org/10.1016/i.compositesb.2016.10.058

[36] Araújo A, Botelho G, Oliveira M, Machado AV. Influence of clay organic modifier on the thermal-stability of PLA based nanocomposite. Applied Clay Science 2014; 88-89: 144-150. https://doi.org/10.1016/i.clay.2013.12.005

[37] Pinto VC, Ramos T, Alves ASF, Xavier J, Tavares PJ, Moreira, R.M. Guedes PMGP. Dispersion and failure analysis of PLA, PLA/GNP and PLA/CNT-COOH biodegradable nanocomposite by SEM and DIC inspection. Engineering Failure Analysis 2017; 71: 63-71. https://doi.org/10.1016/i.engfailanal.2016.06.009

[38] Ayana B, Suin S, Khatua BB. Highly exfoliated eco-friendly thermoplastic starch (TPS)/poly (lactic acid)(PLA)/clay nanocomposite using unmodified nanoclay. Carbohydrate Polymers 2014; 110: 430439.

https://doi.org/10.1016/i.carbpol.2014.04.024 